\title{
P300 and delay-discounting in obsessive-compulsive disorder
}

\author{
Vera Flasbeck $^{1}\left[\right.$ B Björn Enzi $^{1} \cdot$ Christina Andreou $^{2} \oplus \cdot$ Georg Juckel $^{1} \mathbb{D} \cdot$ Paraskevi Mavrogiorgou $^{1}$
}

Received: 27 October 2020 / Accepted: 4 July 2021 / Published online: 13 July 2021

(c) The Author(s) 2021

\begin{abstract}
Previous research showed that dysfunctions of fronto-striatal neural networks are implicated in the pathophysiology of obsessive-compulsive disorder (OCD). Accordingly, patients with OCD showed altered performances during decision-making tasks. As P300, evoked by oddball paradigms, is suggested to be related to attentional and cognitive processes and generated in the medial temporal lobe and orbitofrontal and cingulate cortices, it is of special interest in OCD research. Therefore, this study aimed to investigate P300 in OCD and its associations with brain activity during decision-making: P300, evoked by an auditory oddball paradigm, was analysed in 19 OCD patients and 19 healthy controls regarding peak latency, amplitude and source density power in parietal cortex areas by sLORETA. Afterwards, using a fMRI paradigm, Blood-oxygen-leveldependent (BOLD) contrast imaging was conducted during a delay-discounting paradigm. We hypothesised differences between groups regarding P300 characteristics and associations with frontal activity during delay-discounting. The P300 did not differ between groups, however, the P300 latency over the P4 electrode correlated negatively with the NEO-FFI score openness to experience in patients with OCD. In healthy controls, P300 source density power correlated with activity in frontal regions when processing rewards, a finding which was absent in OCD patients. To conclude, associations of P300 with frontal brain activation during delay-discounting were found, suggesting a contribution of attentional or context updating processes. Since this association was absent in patients with OCD, the findings could be interpreted as being indeed related to dysfunctions of fronto-striatal neural networks in patients with OCD.
\end{abstract}

Keywords OCD $\cdot$ Event-related potentials $\cdot$ P300 $\cdot$ Delay discounting $\cdot$ Neuroimaging $\cdot$ fMRI

\section{Introduction}

Obsessive-compulsive disorder (OCD) is a psychiatric condition that involves neurobiological dysfunctions of frontostriatal neural networks. Neuroimaging methods have contributed to a better understanding of the pathogenesis of this disorder, however, findings are not consistent across all studies. Although efficacious treatments have been developed and established, patients in clinical settings often show inadequate responses to treatment attempts. Several studies indicate a neurobiological basis of OCD, resulting in two main

Georg Juckel

georg.juckel@rub.de

1 Department of Psychiatry, LWL-University Hospital, Ruhr University Bochum, Alexandrinenstr. 1, 44791 Bochum, Germany

2 Department of Psychiatry and Psychotherapy, University Hospital Lübeck (UKSH), Ratzeburger Allee 160, 23538 Lübeck, Germany hypotheses: neuroanatomical and serotonergic. Studies using neurochemical and neuroimaging methods have shown that various neurotransmitters are implicated in the pathophysiology of this disorder, including serotonin [1], dopamine [2] and glutamate [3]. To date, the highest impact is attributed to the neurochemical model of OCD that postulates a central serotonergic dysfunction, mainly based on the efficacy of selective serotonin reuptake inhibitor (SSRI) treatment in OCD. However, the underlying therapeutic mechanism of SSRIs in OCD remains unclear because there are discrepant findings across studies of structural and functional brain changes before and after SSRI treatment in patients with OCD [4].

In addition, it has been suggested that OCD is caused by abnormal activity in the cortico-striato-thalamo-cortical (CSTC) circuits, including the orbitofrontal cortex (OFC), the striatum within basal ganglia and the thalamus $[5,6]$, which is summarised as the neuroanatomical hypothesis. It was postulated that OCD symptoms may be related to increased activity in the $\mathrm{OFC}$, as a consequence 
of diminished inhibitory effects of the striatum (especially the globus pallidus internus) on the thalamus. Furthermore, this hypothesis suggests that OCD could be associated with dysfunctional cognitive and metacognitive processing. In order to investigate the proposed OFC hyperactivity in OCD patients, the $\mathrm{P} 300$ component of auditory event-related potentials (ERPs) could be a suitable tool, as it is proposed that P300 is generated in the medial temporal lobe, OFC and cingulate cortex [7]. Furthermore, the appearance of $\mathrm{P} 300$ during oddball paradigms is suggested to reflect cognitive and attentional processes. In detail, the P300 occurs with a latency of approximately $300-500 \mathrm{~ms}$ after the occurrence of rare or task-related stimuli or after a target stimulus (compared to non-target stimuli) and was measured over frontalto-temporal and parietal electrodes.

A tremendous range of literature revealed inconsistent cognitive neuropsychological findings e.g. attentional deficits in OCD, which were found using various behavioural tests. The investigation of biological markers, such as the P300 component, also contributed to the understanding of cognitive alterations in OCD. Unfortunately, inconsistent P300 abnormalities were reported for patients with OCD with several previous studies reporting shortened latencies [8-12] and increased amplitudes [8, 13-15], whereas other studies showed decreased P300 amplitudes in these patients $[16,17]$. Thus, additional future research is necessary to clarify the P300 alterations and in OCD, which was one aim of the present study.

Further studies aimed to investigate ERPs, especially the P300, and their changes during decision-making tasks [18-22]. Here, the P300 was found to be linked to risky decision making, with larger P300 amplitudes associated with riskier behaviours. Besides these findings, only a few studies exist that were interested in specific delay-discounting effects on P300, such as the effect of intertemporal choices [23-26].

Research regarding decision making in difficult tasks, such as the Iowa Gambling Task [27] and the Game of Dice Task [28], also showed abnormal performances in OCD patients [29-32], but did not clarify which neural processes were altered. Delayed reward discounting is a behavioural economic index of impulsivity and numerous studies have examined delayed reward discounting in substance use disorder $[33,34]$. However, few empirical data is available on delayed reward discounting in patients with OCD [35]. In a series of functional magnetic resonance imaging (fMRI) studies, scientists reported activities primarily within the OFC during delay-discounting tasks [36], therefore, this task may be a suitable tool for assessing the activity state within the OFC. However, it remains unclear whether neurotransmitters, especially serotonin, are involved in the abnormalities of the CSTC circuit in OCD. In a recently published study, using the same dataset as the present investigation, the results indicated that activation of dorsolateral and medial prefrontal cortex (PFC) as well as ventral striatum activation differed between OCD patients and healthy volunteers during the delay-discounting paradigm (immediate reward vs. control) [37]. Based on previous literature and theoretical considerations, we propose that $\mathrm{P} 300$, as a marker of cognitive and attentional processes, would be increased in OCD, due to altered attention and accelerated cognitive and motor processes. Higher P300 processing would be observable as lower amplitudes and longer latencies [38]. Moreover, it would be of interest to examine whether general cognitive processing would be associated specifically with OFC activity in patients with OCD. The OFC activity would be of special interest in OCD since it is suggested to be a region which is functionally altered in OCD, during a task that is known to elicit deviating behaviour in OCD patients compared und unaffected individuals.

To our knowledge, the approach of combining oddball P300 measures with BOLD contrasts of delay-discounting has not been investigated previously and is the secondary aim of the present investigation. We combined the previously performed fMRI analysis during the delayed discounting paradigm with EEG, cortical and source analysis concerning the P300 component, whereby these measurements were conducted consecutively. For the fMRI analysis, functional BOLD signal was extracted from selected anatomically defined regions of interest in the OFC, next to whole brain fMRI analysis [37].

We hypothesised that a significant association of P300 during EEG recording would be found with activation of the reward processing system during the fMRI-delay-discounting task. Here, we proposed that a higher cognitive demand during the $\mathrm{P} 300$ paradigm would be related to increased OFC activity. In addition, we expected to detect differences in P300 amplitude and latency between healthy participants and patients with OCD. More detailed, we hypothesised to find longer latencies and decreased amplitudes in patients with OCD, since we suggested increased cognitive impairment in these patients.

\section{Method}

\section{Subjects}

Nineteen patients (eight females; mean age $33.37 \pm 11.73$ years) with unequivocal diagnosis of OCD were recruited. Diagnosis was based on the diagnostic criteria of the 4th edition of the Diagnostic and Statistical Manual of Mental Disorders (DSM-IV) [39] and 10th revision of the International Statistical Classification of Diseases and Related Health Disorders (ICD-10: F42.X) [40]. Exclusion criteria included organic disorders according to the ICD-10 
(F0X) or recent concomitant neurological or other medical disorders and the presence of severe alcohol or substance abuse. No patient met the criteria for Tourette syndrome or any psychotic disorder. Table 1 shows the sociodemographic and clinical data of the nineteen patients included in the study. Seventeen patients were medicated at the time of assessment: Thirteen were taking SSRIs (fluoxetine, 40-60 mg/day; sertraline, 50-150 mg/day; escitalopram,

Table 1 Sociodemographic and clinical characteristics of patients with obsessive-compulsive disorder (OCD) and healthy controls

\begin{tabular}{|c|c|c|}
\hline & $\operatorname{OCD}(n=19)$ & Controls $(n=19)$ \\
\hline \multicolumn{3}{|l|}{ Gender } \\
\hline Female & $8(42.1 \%)$ & $8(42.1 \%)$ \\
\hline Male & $11(57.9 \%)$ & $11(57.9 \%)$ \\
\hline Age (years) & $33.37 \pm 11.73$ & $31.63 \pm 10.79$ \\
\hline \multicolumn{3}{|l|}{ Marital status } \\
\hline Married & $3(15.8 \%)$ & $4(21.1 \%)$ \\
\hline Cohabitating & $10(52.6 \%)$ & $8(42.1 \%)$ \\
\hline Single & $6(31.6 \%)$ & $7(36.8 \%)$ \\
\hline \multicolumn{3}{|l|}{ Education } \\
\hline Upper grade & $15(78.9 \%)$ & $16(84.2 \%)$ \\
\hline Middle grade & $4(21.1 \%)$ & $3(15.8 \%)$ \\
\hline Lower grade & 0 & 0 \\
\hline \multicolumn{3}{|l|}{ Occupational status } \\
\hline Employed & $8(42.1 \%)$ & $13(68.4 \%)$ \\
\hline Unemployed & $3(15.8 \%)$ & 0 \\
\hline Student & $6(31.6 \%)$ & $6(31.6 \%)$ \\
\hline Retired, unable to work & $2(10.2 \%)$ & 0 \\
\hline Duration of illness (years) & $14.27 \pm 12.39$ & \\
\hline Age of onset (years) & $19.21 \pm 6.71$ & \\
\hline HAM-D & $12.42 \pm 6.13$ & \\
\hline BDI & $14.68 \pm 10.12$ & $1.42 \pm 2.01^{*}$ \\
\hline Y-BOCS, obsessions & $10.74 \pm 2.53$ & \\
\hline Y-BOCS, compulsions & $10.53 \pm 3.73$ & \\
\hline Y-BOCS, total & $21.79 \pm 6.59$ & \\
\hline MOCI & $14.84 \pm 5.93$ & $3.89 \pm 2.96^{*}$ \\
\hline STAI I & $42.89 \pm 13.72$ & $30.21 \pm 5.06^{*}$ \\
\hline STAI II & $50.26 \pm 11.75$ & $30.58 \pm 7.95^{*}$ \\
\hline CGI & $4.58 \pm 0.69$ & $1.00 \pm 0^{*}$ \\
\hline MWST-IQ & $109.63 \pm 12.08$ & $119.58 \pm 13.22 *$ \\
\hline NEO-FFI, total & $2.77 \pm 0.55$ & $2.69 \pm 0.69$ \\
\hline BIS-11, total & $59.00 \pm 8.72$ & $56.37 \pm 7.43$ \\
\hline PSP & $67.16 \pm 14.08$ & $100^{*}$ \\
\hline
\end{tabular}

Values are numbers and percentages or means and standard deviations (SD); $* p<0.05$

$H A M-D$ Hamilton Depression Scale, BDIBeck Depression Inventory, $Y$-BOCS Yale-Brown Obsessive Compulsive Scale, MOCIMaudsley Obsessive-Compulsive Inventory, STAIStait-Trait Anxiety Inventory, CGIClinical Global Impression scale, MWST-IQ MehrfachWortschatztest, NEO-FFINEO Five-Factor Inventory, BIS-11 Barratt Impulsiveness Scale, PSP Personal and Social Performance scale
$10 \mathrm{mg} /$ day; citalopram, 20-60 mg/day), one received clomipramine $(200 \mathrm{mg} /$ day $)$ and three received a serotonin-norepinephrine reuptake inhibitor (SNRI: venlafaxine, $300 \mathrm{mg} /$ day, $n=2$; or duloxetine, $90 \mathrm{mg} / \mathrm{day}, n=1$ ). None of the patients were engaged in cognitive-behavioural therapy during the study period.

Nineteen healthy volunteers (eight females; mean age $31.63 \pm 10.79$ years) without any neurological or psychiatric disorder in their personal or family history served as a control group, matched for age, gender, education level and handedness (18 right-handed). The volunteers underwent the Mini International Neuropsychiatric Interview for DSM-IV and ICD-10 disorders (MINI-PLUS) [41, 42] and psychometric tests for obsessive-compulsive, depressive and anxiety symptoms.

All participants underwent the same study design with fMRI, P300-based electroencephalography (EEG) and psychometric assessments within a few hours on a single day. All participants started with the EEG recording and questionnaires in the morning and the fMRI recording was done in the afternoon. For one control participant, the fMRI recording was done the next morning, still within $24 \mathrm{~h}$.

\section{Clinical assessment}

The severity of OCD symptoms was assessed by the Yale-Brown Obsessive Compulsive Scale (Y-BOCS) [43, 44] and the Maudsley Obsessive-Compulsive Inventory (MOCI) [45]. To validate the presence of OCD symptoms, we used the Y-BOCS symptom checklist.

The severity of depressive symptoms was assessed using the Hamilton Depression Rating Scale (HAM-D) [46] and self-ratings were assessed by the Beck Depression Inventory (BDI) [47]. Anxiety symptoms were measured using the State-Trait Anxiety Inventory (STAI I and II) [48, 49]. The overall severity of the psychiatric disorder was quantified using the Clinical Global Impression (CGI) score (NIMH) [50]. Psychosocial functioning was measured by the Personal and Social Performance scale (PSP) [51] and impulsivity was assessed by the Barratt Impulsiveness Scale (BIS-11) [52, 53]. The NEO Five-Factor Inventory (NEOFFI) [54] was used to assess personality characteristics such as extraversion, neuroticism and conscientiousness. Participants' verbal intelligence was estimated with the Mehrfachwahl-Wortschatztest (MWT) [55].

\section{P300}

During the oddball paradigm, two different kinds of stimuli (80\% non-target, 400 sinus tones, $500 \mathrm{~Hz} ; 20 \%$ target stimuli, 100 sinus tones, $1000 \mathrm{~Hz}$ ) were presented in pseudorandomized order ( $80 \mathrm{~dB}$ SPL, $40 \mathrm{~ms}$ duration, $10 \mathrm{~ms}$ rise and fall time, interstimulus interval $1.5 \mathrm{~s}$ ) via headphones (Sony 
Stereo Headphones MDR-1A, Sony ${ }^{\circledR}$ Corporation) and Presentation ${ }^{\circledR}$ software (Neurobehavioral Systems, Inc., Version 14.9, Berkeley, CA: www.neurobs.com) to the participants. All participants were instructed to press a response button with their dominant hand whenever they heard the target stimulus.

\section{EEG recording and data analysis}

Subjects sat in a comfortable armchair in an electrically shielded and sound-attenuated room. Auditory-evoked potentials were recorded with 32 non-polarizable $\mathrm{Ag}-\mathrm{AgCl}$ electrodes referred to as $\mathrm{FCz}$, placed according to the international 10/20 system. Impedances were kept at $5 \mathrm{k} \Omega$ or below. EEG was filtered using a bandpass of $0.16-70 \mathrm{~Hz}$ and data were collected at a sampling rate of $250 \mathrm{~Hz}$ using a BrainAmp MR amplifier and BrainVision recorder software (Version 1.20.001: Brain Products GmbH, Gilching, Germany). Data analysis was performed using the BrainVision Analyzer 2.0 (Version 2.01.3931: Brain Products GmbH, Gilching, Germany). The recorded data were re-referenced to the mastoid electrodes and filtered using bandpass and notch filters $(0.5-20 \mathrm{~Hz}$ and $50 \mathrm{~Hz})$. For artifact rejection, all trials were excluded if the voltage exceeded $\pm 70 \mu \mathrm{V}$ in any channel. The epochs ( -200 to $1000 \mathrm{~ms}$ ) were averaged separately for the target and non-target stimuli and corrected to the baseline (-200 ms). Only subjects with at least 40 trials free of artefacts for both stimuli were included.

The P300 amplitudes and peak latencies were analysed (P300 defined as the most positive peak within 250-500 ms after stimuli onset for the P3, P4 and Pz electrodes because P300 is suggested to be maximal over parietal electrodes [56]. This was also true for the present study. As shown in Fig. 1, the maximal amplitude was recorded over parietal electrodes, independent of group.

\section{sLORETA analysis}

For the analysis of source P300 data, sLORETA Software [57] was used. Therefore, the re-referencing was conducted to the average of all electrodes and the average of segments from target tones were exported. First, we compared the current density power, measured as $\mu \mathrm{A} / \mathrm{mm}^{2}$, between groups. Therefore, a voxel-by-voxel $t$-test was performed on logtransformed data for the timeframe from 240 to $580 \mathrm{~ms}$ after target tone. As previously done, a non-parametric randomisation approach was applied [58] for correction for multiple comparisons. In addition, a ROI analysis was performed to investigate the electric neuronal activity as current source density power in the parietal cortices comprising all voxels of the Brodmann areas 5, 7, 39 and 40 (see Fig. 2). Here, Brodmann areas belonging to the posterior parietal cortex were selected, due to the involvement of this regions in higher-order functions [59]. Since we are interested in cognitive processing, as represented by $\mathrm{P} 300$, we chose the posterior parietal cortex and excluded anterior parietal cortical regions, which are also involved in somatosensory processes.

In this study, the BA 5-ROI covered a region extended in Talairach space from $x$ : $0-40$ and 0 to $-40, y:-35$ to -50 , $z: 50-70$ and included all voxels. The BA 7-ROI covered the region from $x: 0$ to -40 and $40, y:-50$ to $-80, z: 30-70$, also including all voxels. Similarly, BA 39 extended from $x$ : - 35 to -60 and 35-60, $y:-55$ to $-80, z: 10-40$ and BA 40 BA 39 from $x$ : -25 to -65 and 25-65, $y:-20$ to $-60, z$ : 15-60. The ROI analysis was done with the "ROI-Extractor" tool which averages the CSD values in the specified voxels. The brain model of LORETA is based on the Montreal Neurological Institute average MRI brain map (MNI 152), while the solution space is limited to the cortical grey matter, comprising 6239 voxels of $5-\mathrm{mm}^{3}$ resolution. The mean source density power at each ROI within the time frame of 240-580 ms after target tone onset was computed for every
Fig. 1 Topographic maps of brain activity after onset of the target tones from 0 to $500 \mathrm{~ms}$ in healthy controls (left) and patients with OCD (middle), measured by EEG. The right topographic maps show the difference between patients with OCD and healthy controls

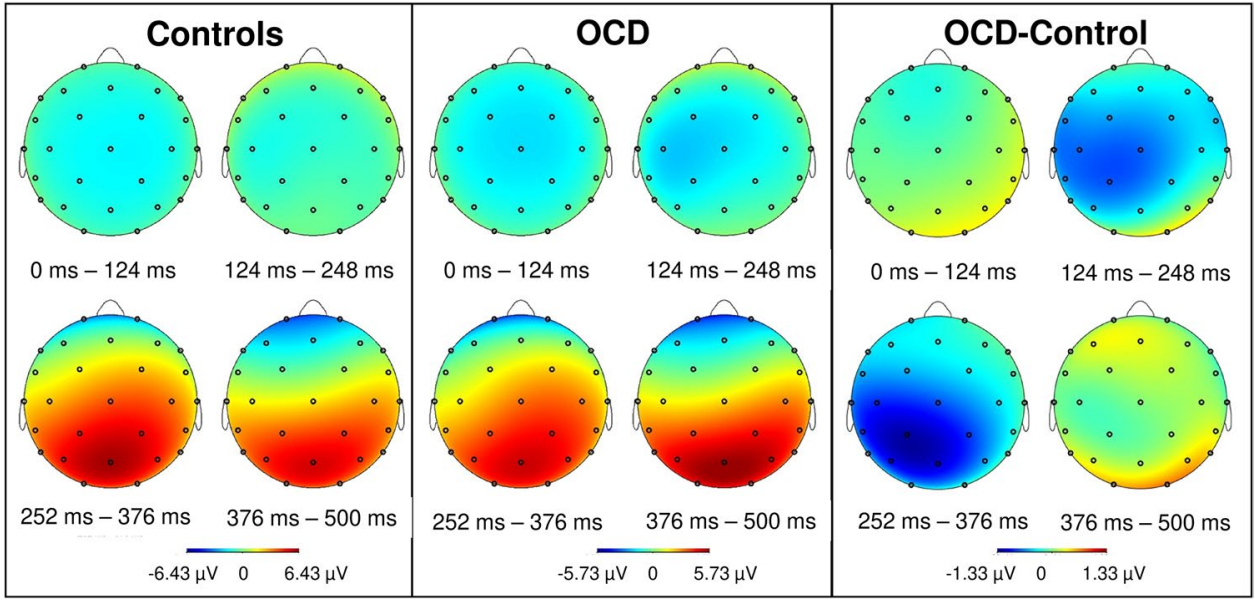




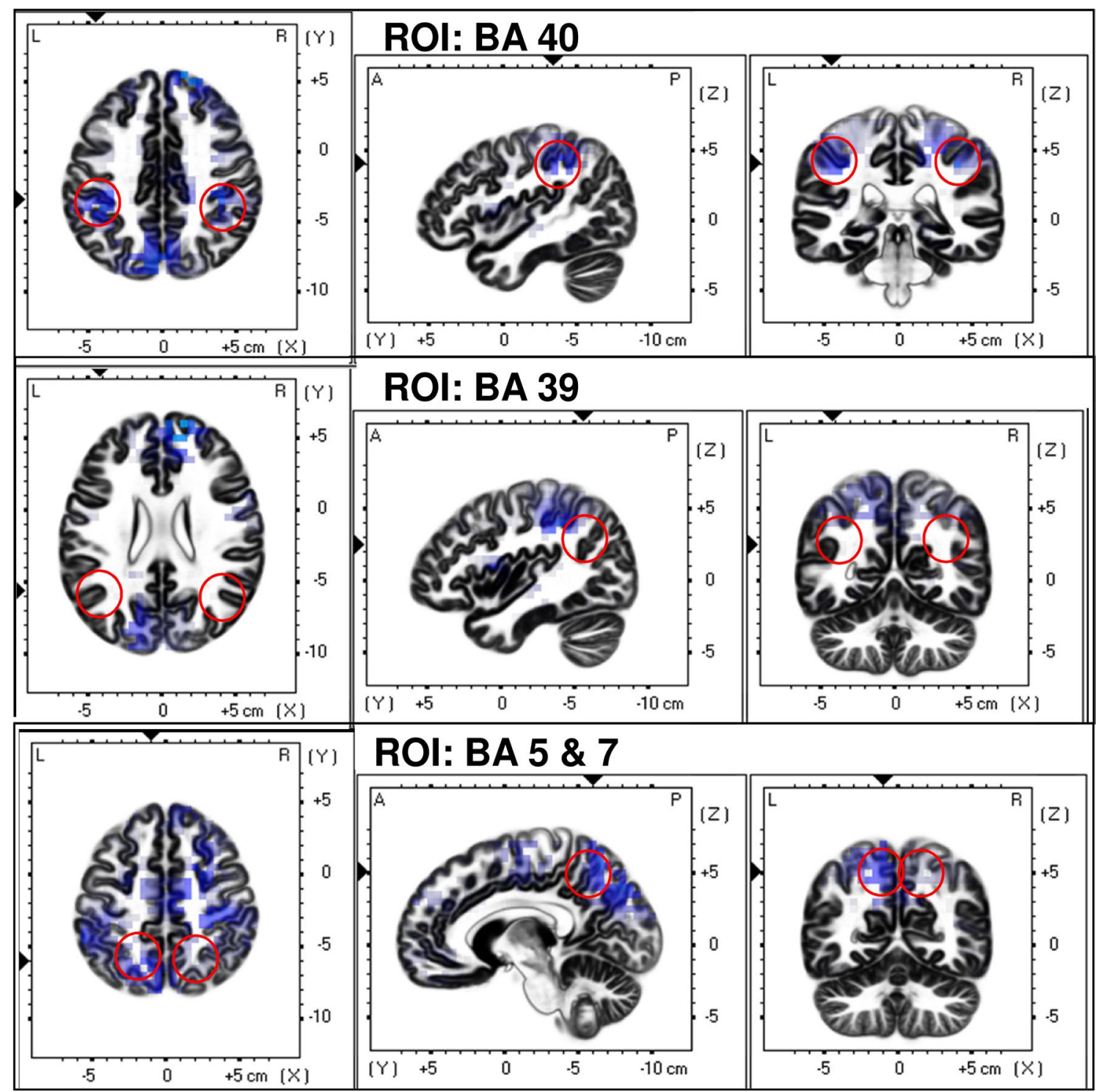

Fig. 2 Comparison of brain activity for the P300 between patients with OCD and healthy controls by sLORETA. Here, the ROIs, namely BA39, BA4, BA 5 and BA7 are marked

participant. Finally, we calculated the average of all ROIs for each participant.

\section{Behavioural practice session of delay-discounting}

We used a slightly modified version of an established decision-making paradigm described previously by Peters and Büchel [36]. Before scanning, all subjects completed an identical practice version of the task. The results of the pretest were used to adequately compute offers for the fMRI sessions and estimate the individual discounting rate $k$. The participants were ask to choose between a fixed immediate reward of $€ 20$ and higher but delayed rewards in 2, 7, 14, 28 or 40 days. The delayed rewards were computed individually for each participant to ensure that the delayed offer was chosen in approximately $50 \%$ of all trials. The amount of money at which the participants switched from accepting the immediate fixed reward to the delayed reward, also called the indifference amount, was calculated and converted into proportions of the fixed reward. Based on the hyperbolic function, these data were used to obtain the best-fitting discounting parameter $k$.

\section{fMRI}

During fMRI, each trial began with a short cue symbol $(500 \mathrm{~ms})$ followed by presentation of the reward options (immediate vs. delayed) for $2000 \mathrm{~ms}$. After a jittered 
anticipation period of $2000-3000 \mathrm{~ms}$, participants had to choose the preferred reward option using an MR-compatible response box. After a short feedback period of $2000 \mathrm{~ms}$, a jittered intertrial interval (3000-5000 ms) was presented. Each delay condition consisted of 14 trials, resulting in 70 trials per run. During 10 control condition trials, the participants were asked to choose either the left or right side of the screen without getting a reward. The experiment consisted of two runs of approximately 18 min each. Functional data were collected using a 3-T whole-body MRI system (Philips Achieva 3.0 T TX) equipped with a 32-channel Philips SENSE head coil. A total of $32 \mathrm{~T} 2 *$-weighted echo-planar images per volume with blood-oxygen-level-dependent (BOLD) contrast were obtained using a sensitivity-encoded single-shot echo-planar imaging protocol (SENSE-sshEPI). For further details of fMRI procedures, see our previous publications $[37,60]$. The functional data were preprocessed and statistically analysed using SPM8 (Wellcome Department of Cognitive Neuroscience, University College London, UK: http://www.fil.ion.ucl.ac.uk) and MATLAB 7.11 (Mathworks Inc., Natick, MA, USA). In addition to the whole brain analyses described elsewhere [37, 60], activity in anatomically defined regions of interest based on our previous work were analysed. These regions, namely the left and right OFC, respectively (inferior frontal gyrus, orbital part; superior frontal gyrus, medial orbital part (SFG/MO); middle frontal gyrus, orbital part; superior frontal gyrus, orbital part; gyrus rectus) were generated using both AAL and WFU PickAtlas software. More in detail, percent signal changes (based on the beta values for each event) derived from the above-mentioned regions were extracted using the standard routines implemented in MarsBar [61].

\section{Statistical analysis}

Statistical analyses of the data were performed using IBM SPSS Statistics for Windows, Version 25.0 (IBM Corp., Armonk, NY, USA). The analyses of P300, questionnaire data and neuroimaging results were performed with nonparametric Mann-Whitney $U$ tests and Spearman correlation coefficients due to violations of normal distribution. Statistical significance was defined as $p<0.05$. For correlations of questionnaires and P300 data, Bonferroni correction due to multiple testing was applied, whereby related variables, e.g. P3 amplitude and P4 amplitude, were considered as one factor. The $p$-value threshold was shifted accordingly (for eight questionnaires: BDI, MOCI, STAI, CGI, MWST-IQ, NEO-FFI, BIS-11, PSP and three P300 variables: latency, amplitude and source density power: $p=0.05 / 11=0.0045$ ). In the patients group, additional correlations were calculated for Y-BOCS scores. For correlations between fMRI data, based on ROI-analysis, and P300 (source P300 data), the significance level was set to $p<0.025$ (since OFC regions are related and considered as one factor; correction for testing of left and right hemisphere was applied). For correlations between functional BOLD responses and P300, the significance threshold was adjusted for six different, unrelated regions and P300 $(p=0.05 / 7=0.007)$. The correlations with fMRI data were performed for the three different contrasts separately, i.e. [ $\Delta$ immediate reward - control], [ $\Delta$ delayed reward-control] and $[\Delta$ immediate rewarddelayed reward].

\section{Results}

\section{Sociodemographic and clinical findings}

Patients with OCD reported significantly more severe psychopathological symptoms with higher scores in depression, anxiety and obsessive-compulsive symptom questionnaires compared to the control group (Table 1). Regarding personality characteristics, patients showed lower neuroticism (OCD: $M=1.31, \mathrm{SD}=0.69$; control: $M=2.27, \mathrm{SD}=0.62$; $U=48.0, Z=-3.87, p<0.001)$ and higher extraversion (OCD: $M=2.65, \mathrm{SD}=0.49$; control: $M=2.05$, $\mathrm{SD}=0.60$; $U=70.0, Z=-3.23, p=0.001)$ and openness to experience (OCD: $M=2.72, \mathrm{SD}=0.61$; control: $M=2.32$, $\mathrm{SD}=0.48 ; U=82.5, Z=-2.86, p=0.003)$. No differences between groups were observed for agreeableness and conscientiousness.

Although no differences between groups were observed for the BIS-11 total score, distinct differences emerged for the BIS-11 subscales, with OCD patients reaching lower scores in attentional impulsiveness (OCD: $M=12.58$, $\mathrm{SD}=3.08 ;$ control: $M=17.63, \mathrm{SD}=4.0 ; U=42.5$, $Z=-4.05, p<0.001)$ and higher scores in motor impulsiveness compared to the control group (OCD: $M=21.47$, $\mathrm{SD}=2.59$; control: $M=19.32, \mathrm{SD}=3.13 ; U=104.0$, $Z=-2.25, p=0.025$ ).

\section{EEG: P300 findings}

The waveforms evoked by the target tones are shown in Fig. 3 for the parietal electrodes of interest (P3, P4 and Pz) and for additional central $(\mathrm{C} 3, \mathrm{C} 4$ and $\mathrm{Cz})$ and frontal (F3, $\mathrm{F} 4$ and $\mathrm{Fz}$ ) electrodes. Here, the parietal maximum of the P300 component is again observable. P300 amplitude and latency did not differ significantly between OCD patients and controls at P3, P4 and Pz. In OCD patients, amplitudes reached $8.5 \mu \mathrm{V}(\mathrm{SD}=4.6), 7.0 \mu \mathrm{V}(\mathrm{SD}=3.3)$ and $7.0 \mu \mathrm{V}$ $(\mathrm{SD}=3.5 \mu \mathrm{V})$ and latencies were $375.6 \mathrm{~ms}(\mathrm{SD}=53.0)$, $366.3 \mathrm{~ms}(\mathrm{SD}=50.8)$ and $373.7 \mathrm{~ms}(\mathrm{SD}=47.0)$ for $\mathrm{Pz}$, P3 and P4, respectively. In healthy controls, amplitudes reached $8.5 \mu \mathrm{V}(\mathrm{SD}=3.6), 6.9 \mu \mathrm{V}(\mathrm{SD}=3.1)$ and $6.8 \mu \mathrm{V}$ $(\mathrm{SD}=2.9)$. There was a visual tendency towards shorter 


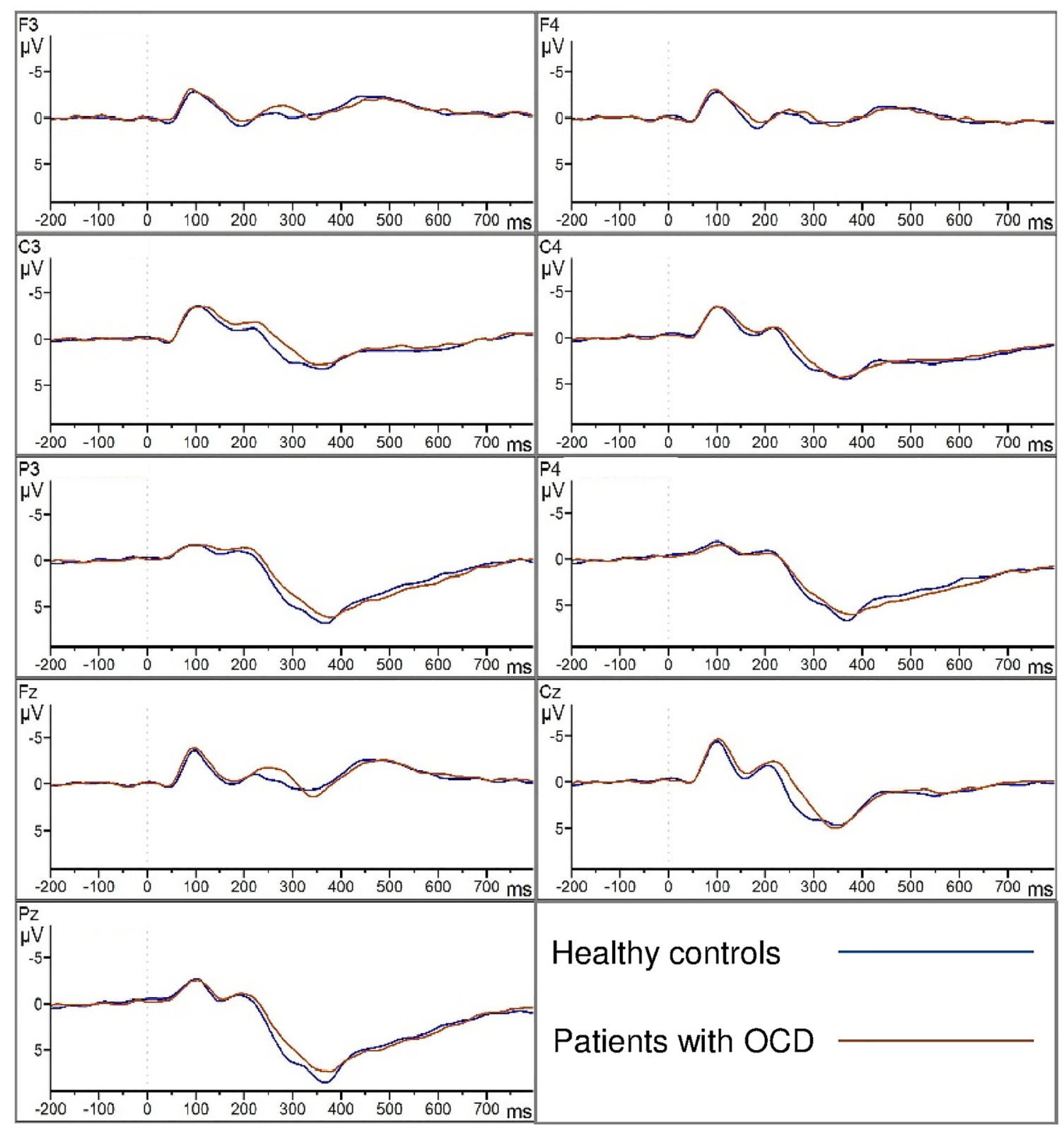

Fig. 3 Grand-average waveforms showing the ERP components evoked by the target tones during the oddball paradigm. The waveforms of electrodes F3, F4 (first line), C3, C4 (second line), P3, P4

latencies within the control group $(357.5 \mathrm{~ms}, \mathrm{SD}=28.5$; $357.0 \mathrm{~ms}, \mathrm{SD}=23.5 ; 364.0 \mathrm{~ms}, \mathrm{SD}=36.9)$ for $\mathrm{Pz}, \mathrm{P} 3$ and P4, respectively (see Fig. 3), compared to patients with OCD. This tendency is also visible in Figs. 1, which shows the parietal maximum in controls in the time window of 252-376 ms, and for patients with OCD, the most positive activity is observable in the last timeframe from 376 to $500 \mathrm{~ms}$.

Similar to the cortical P300 results, no differences between groups were found for source P300 results as calculated by sLORETA (maximum $t=2.419, p<0.05$; all (third line), $\mathrm{Fz}, \mathrm{Cz}$ (forth line) and $\mathrm{Pz}$ and the legend (sixth line) are presented. Healthy controls (blue) and patients with OCD (brown) are indicated by separate lines

$p$ 's $>0.05$; see Fig. 4). Accordingly, no differences were found for the ROI analyses (Fig. 2).

\section{Correlations between P300 (EEG) and clinical outcome}

In the group of healthy controls, questionnaire scores correlated with P300 characteristics, as measured by EEG. However, after correction for multiple testing (for nine questionnaires: BDI, MOCI, STAI, CGI, MWST-IQ, NEO-FFI, BIS-11, PSP and three P300 variables: latency, amplitude 
Fig. 4 T-test comparison of current source density power by sLORETA between patients with OCD and healthy controls. The marked differences did not reach statistical significance. In a, parietal brain regions are shown and in $\mathbf{b}$ frontal regions are visible
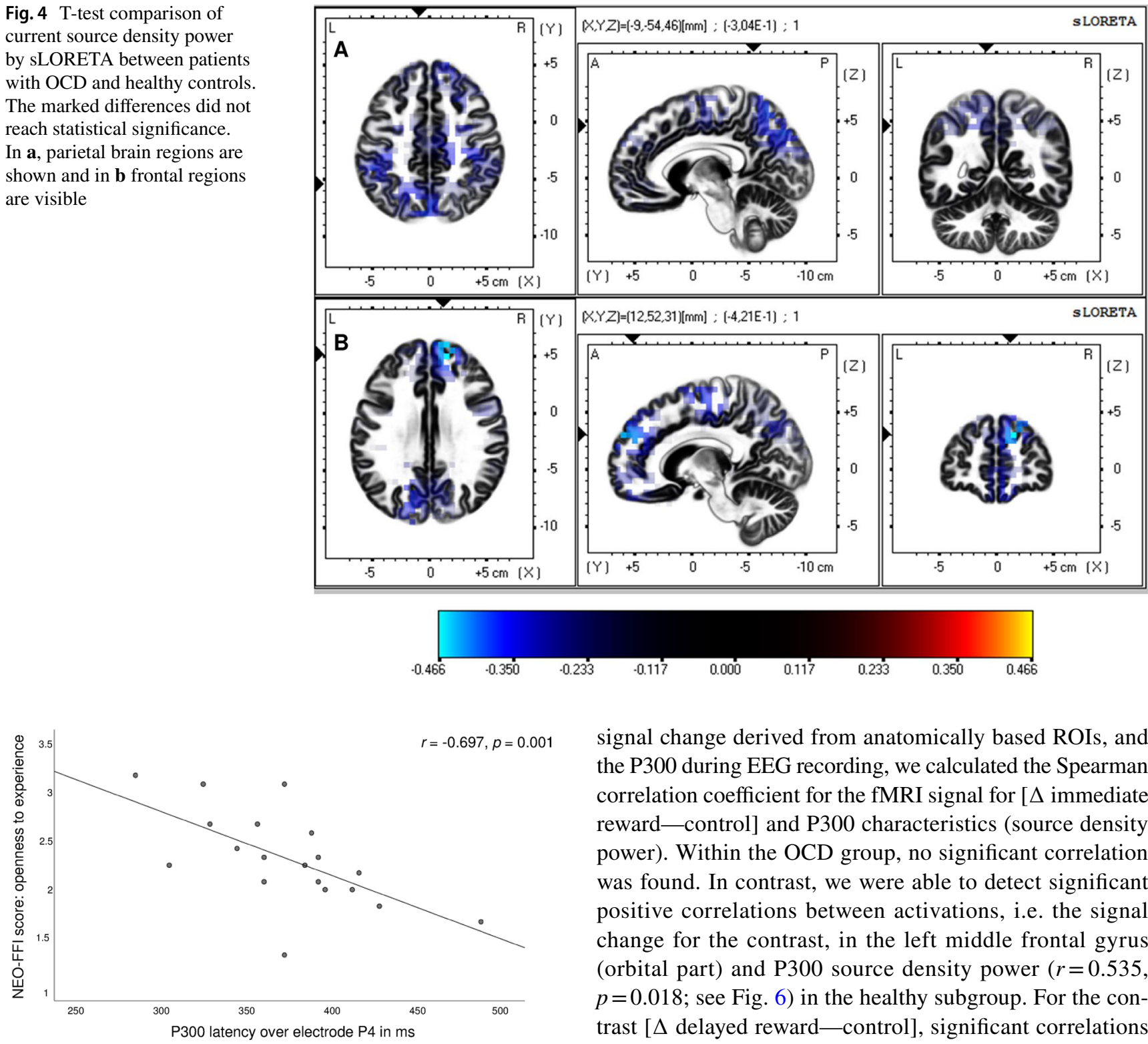

Fig. 5 Correlation between the NEO-FFI score openness to experience score and the P300 latency over the P4 electrode in patients with OCD

and source density power: $p=0.05 / 11=0.0045$ ), no correlation remained significant. In the patients group, a significant correlation between the NEO-FFI openness to experience score and the P4 P300 latency survived Bonferroni correction ( $r=-0.697, p=0.001$; see Fig. 5 ; correction for all variables mentioned above plus Y-BOCS).

\section{Correlations between P300 (EEG) and ROI-activation (BOLD)}

Regarding a possible relationship between reward-related neuronal activity during fMRI acquisition, extracted as signal change derived from anatomically based ROIs, and the P300 during EEG recording, we calculated the Spearman correlation coefficient for the fMRI signal for [ $\Delta$ immediate reward—control] and P300 characteristics (source density power). Within the OCD group, no significant correlation was found. In contrast, we were able to detect significant positive correlations between activations, i.e. the signal change for the contrast, in the left middle frontal gyrus (orbital part) and P300 source density power $(r=0.535$, $p=0.018$; see Fig. 6 ) in the healthy subgroup. For the contrast [ $\Delta$ delayed reward-control], significant correlations were again only observable in the control group between the signal change in the left middle frontal gyrus (orbital part) and the left superior frontal gyrus (orbital part) and the P300 source density power $(r=0.544, p=0.016)$. For the contrast [ $\Delta$ immediate reward—delayed reward], no significant association was found.

\section{fMRI BOLD responses and correlations with P300}

For brain activations during the fMRI task in both groups, see Table 2 and for details see [37]. In brief, a main effect of task was observable in the bilateral inferior frontal gyrus, the bilateral supramarginal gyrus, the left middle frontal gyrus, the left middle occipital cortex and the angular gyrus. A group effect was observed for the left ventral striatum/putamen and the right dorsolateral prefrontal cortex. Correlations between these functional BOLD measures (FOI), based 
Fig. 6 Correlations between activation in the left middle frontal gyrus (orbital part) for the difference $[\Delta$ immediate reward - control] and the P300 power over left parietal brain areas for healthy controls and patients with OCD

Table 2 Activations in healthy subjects and patients with obsessive-compulsive disorder (OCD)
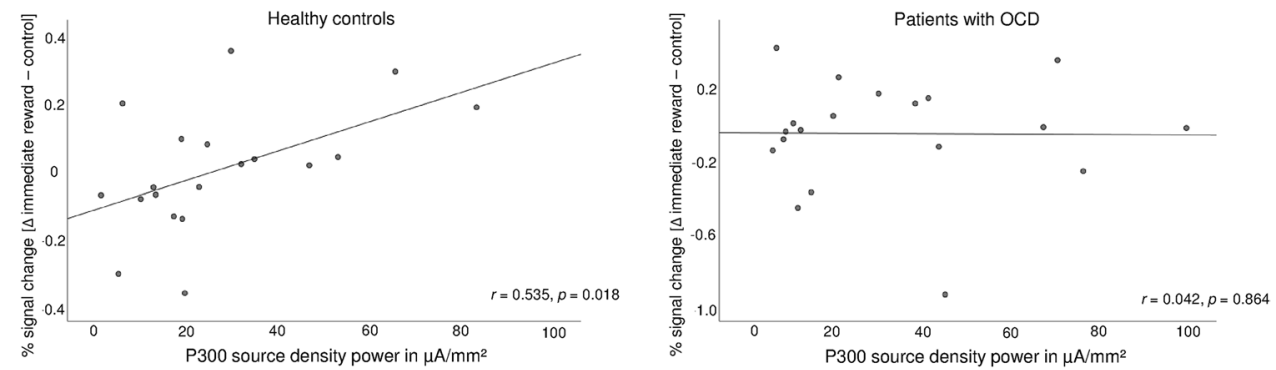

\begin{tabular}{|c|c|c|c|c|c|}
\hline & $\begin{array}{l}\text { Hemi- } \\
\text { sphere }\end{array}$ & Region & Extent $k$ & $Z$ value & Statistical value ${ }^{\mathrm{a}}$ \\
\hline \multicolumn{6}{|c|}{ F-contrast [main effect of task] collapsed over groups } \\
\hline$-38,6,28$ & $\mathrm{~L}$ & Inferior frontal gyrus, opercular part & 24 & 4.94 & 16.89 \\
\hline$-58,-34,34$ & $\mathrm{~L}$ & Supramarginal gyrus & 69 & 5.09 & 17.93 \\
\hline $60,-38,34$ & $\mathrm{R}$ & Supramarginal gyrus & 81 & 5.23 & 18.91 \\
\hline$-34,28,38$ & $\mathrm{~L}$ & Middle frontal gyrus/dlPFC & 31 & 4.88 & 16.51 \\
\hline $56,12,8$ & $\mathrm{R}$ & Inferior frontal gyrus, opercular part ${ }^{\mathrm{b}}$ & 16 & 3.51 & 9.06 \\
\hline$-30,-76,22$ & $\mathrm{~L}$ & Middle occipital cortex ${ }^{c}$ & 50 & 4.24 & 12.64 \\
\hline $28,-54,42$ & $\mathrm{R}$ & Angular gyrus ${ }^{c}$ & 12 & 3.95 & 11.13 \\
\hline \multicolumn{6}{|c|}{$\begin{array}{l}\text { T-contrast [Interaction group } \times \text { task], i.e. "immediate reward: accepted" vs. "delayed reward: accepted" in } \\
\text { heathy vs. OCD patients }\end{array}$} \\
\hline$-22,16,-2$ & $\mathrm{~L}$ & Putamen/ventral striatum ${ }^{\underline{b}}$ & 12 & 3.56 & 3.67 \\
\hline $16,20,56$ & $\mathrm{R}$ & dlPFC (BA8) ${ }^{b}$ & 52 & 3.68 & 3.8 \\
\hline
\end{tabular}

Initial threshold $p[\mathrm{FWE}]<0.05$ for an extent $k>10$ voxels or $F>10.0$ for $k>10$

${ }^{\mathrm{a}} t$ or $F$ value. ${ }^{\mathrm{b}} p[\mathrm{FWE}]<0.05$ after small volume correction with $5 \mathrm{~mm}$ radius. ${ }^{\mathrm{c}} p[\mathrm{FWE}]<0.05$ on cluster level. BA Brodmann area, $d I P F C$ dorsolateral prefrontal cortex on the contrasts, and P300 source density power did not survive correction for multiple testing.

\section{Discussion}

The present study investigated P300 ERPs and their associations with fMRI activation in a delay-discounting task in OCD patients and healthy controls. The two matched groups differed regarding psychopathology, personality characteristics and impulsivity but did not differ in P300 amplitudes or latencies or P300 source density power in parietal regions. Thus, our hypothesis that the groups will differ regarding P300 characteristics was not confirmed. Regarding personality characteristics, patients showed lower neuroticism, but higher extraversion and openness to experience. In previous studies, higher neuroticism and lower extraversion has been reported frequently for patients with OCD [62, 63]. Here, the findings also seem inconsistent, whereas it has been proposed by another study that facets of openness may impact on the particular expression and severity of obsessive-compulsive symptoms [64]. In our study, the factor openness was negatively correlated with P300 latency over P4 in the patients group (see Fig. 5). Thus, higher openness is related to smaller peak latencies, i.e. lower controlled processing. This could, very speculatively, interpreted as lower inhibition in individuals scoring high in openness to experience.

Even if patients with OCD did not differ from healthy controls with regard to P300 latencies and amplitudes, a tendency towards prolonged P300 latency was observed for OCD patients. Previous studies reported prolonged latencies and larger P300 amplitudes in OCD [8-14]. However, it should be noted that the existing literature on P300 EEG abnormalities in studies of patients with OCD is rather discrepant. Sanz et al. [17] found lower P300 amplitudes in combination with prolonged P300 latencies in a sample of drug-free adult OCD patients compared to healthy controls. In addition, a trend towards increased P300 amplitude was observed in patients after treatment with clomipramine, whereas, no modification in P300 latency was shown. Dayan-Riva and colleagues [65] utilised pictures showing neutral and angry facial expressions instead of auditory stimuli. They reported higher $\mathrm{P} 3$ amplitudes in patients with OCD compared to unaffected controls for neutral stimuli only, with no differences regarding angry facial expressions [65]. In this study, no differences were found between groups for latencies, suggesting that the different findings observed in OCD patients compared to healthy controls may depend 
crucially on the tasks used. In addition, it is known that P300 latencies have a much lower reliability than P300 amplitudes, whereas, perhaps data on P300 onset latency could have been mixed up with data on P300 peak latency. Most of these studies reported a shortened P300 latency whereas others detected prolonged latencies [9, 17]. In previous studies, shorter latencies in OCD patients were found only for P3b $[8,13,14]$. Thus, recent research brought several arguments for altered P300 amplitudes and more sparse support for latency differences in OCD. Regarding source analysis of P300, less research is existing, whereas, one study reported higher P300-related activity in patients with OCD in the left orbitofrontal cortex, left prefrontal, parietal and temporal areas compared to controls [13]. Thus, there are hints that altered P300 could play a role in OCD, whereas, the results may depend on the tasks used, the sample sizes investigated and medication of samples. Furthermore, the data analysis may have varied across studies, e.g. with regard to peak latency vs. onset latency analysis or the investigation of $\mathrm{P} 3 \mathrm{a}$ and $\mathrm{P} 3 \mathrm{~b}$ subcomponents.

\section{P300 and delay-discounting in OCD}

Previous researchers have revealed that $\mathrm{P} 300$ reflects the updating of cognitive models in order to make an appropriate response in the sense of an evaluation process for making a decision $[22,66]$. In our fMRI study part, as previously reported for the present dataset, it has been shown that activations of dorsolateral PFC and ventral striatum activations differed between OCD patients and control participants during a delay-discounting paradigm (see [37]). Thus, it was known that P300 (context updating) during EEG recording and delay-discounting behaviour and processing were altered in OCD. Therefore, the question was whether P300, measured by EEG, is related to brain activations, measured by fMRI, during decision making, which was the secondary subject of the present study. In healthy participants, source density power of P300 over parietal brain areas correlated positively with activations in the left middle and superior frontal gyri (orbital parts) for the [ $\Delta$ reward-control] contrasts during the fMRI task. No such correlations were found in the patient's group. The correlations in healthy controls are consistent with previous results, showing larger P300 amplitudes in contexts causing higher risk tendencies [21]. Furthermore, Bellebaum et al. [67] reported that P300 was larger for positive outcomes and showed an effect of potential reward magnitude that was independent of valence. Thus, findings regarding the relationship between P300 and decision-making suggested that P300 was modulated by reward magnitude.

This association was absent in patients with $\mathrm{OCD}$, as no correlations of brain activation during the fMRI-task and P300 power density were found. There are several potential reasons for these findings. First, as we found lower scores for attentional impulsiveness in patients with OCD compared to healthy controls, a general reduced attention could attenuate the association of P300 with brain activation during the delay-discounting paradigm. Second, it has been suggested that patients with OCD exhibit prolonged deliberation during decision-making, implicating emotional valence or risk due to altered processing in relevant brain regions, including frontal and limbic regions [68]. Third, previous studies reported impaired adaption of the decision strategy during a decision-making task, suggesting lower flexibility in OCD $[69,70]$. It can be speculated that the reduced flexibility could be related to reduced attention. In summary, previous research indicated decreased flexibility, and therefore, decreased capacity in OCD to focus attention in a goal-directed manner. In addition, deficits may occur due to delayed attention to relevant cues in OCD ([71]; for review, see [72]).

In fact, this interpretation is speculative and not based on our results. Based on our data, one can propose that these negative findings in the patient group could be caused by altered cognitive controlled processing in these patients, whereby controlled processing is not directly related to reward processing in the OFC, a region which is proposed to be hyperactive due to diminished inhibitory effects of the striatum in OCD. Altered activations of the dorsolateral PFC and the ventral striatum has been shown for the present group of patients, wherefore the results suggest that the OCD group showed indeed altered processing in cortico-striato-thalamo-cortical (CSTC) circuits during the fMRI-task. Therefore, the missing link between parietal cognitive processing, measured by EEG, and OFC activation during reward processing in the fMRI scanner in patients might reflect deviating CSTC circuit processing compared to processes observed in healthy individuals. Another possible reason for the missing association between general cognitive processing (EEG), and reward processing, measured by fMRI, in patients with OCD could be a diminishing effect of the psychopharmacological medication the patients received. In the present study, most of the patients received antidepressant medication. However, it has been shown that psychopharmacological medication affect P300 and OFC activity [73, 74]. Therefore, future research also might investigate the effect of psychopharmacological medication in cognitive processing. Finally, the sample sizes were small in the present study, wherefore significant results, also for P300 analyses between groups, would possibly appear in larger samples.

\section{Conclusion}

In the present study, a negative correlation between the factor openness with P300 latency over P4 was observed 
exclusively in the patients group. We found distinct associations in healthy controls showing correlations of brain activation, as measured by fMRI during reward processing with P300 power, which were absent in the group of patients with OCD. Since cognitive processing, as indicated by P300, did not differ between the groups, the missing association in the group of patients with OCD could be interpreted as altered CSTC circuit activity, which would disrupt the association with general cognitive processing observed in unaffected individuals.

\section{Limitations}

Some limitations of this current study should be noted. First, as mentioned above, our sample consists of patients receiving SSRI medication, which may have affected the results. Second, the small sample size does not enable a meaningful investigation of the specific OCD subgroup characteristics or maybe even group differences at all. Furthermore, P300 as well as fMRI BOLD contrasts during the delay-discounting task are both indirect measurements of brain activity. Finally, both measurements were recorded in sequence within a few hours, but not simultaneously, possibly producing a bias. Furthermore, the proportion of trait and state properties of P300 characteristics and brain activity during the delay-discounting task remains difficult to determine exactly.

Funding Open Access funding enabled and organized by Projekt DEAL. This study was supported by the FORUM of Medical Department of Psychiatry of the Ruhr University Bochum (K038-09).

\section{Declarations}

Conflict of interest The authors declare that there is no conflict of interest.

Ethical approval All subjects gave written informed consent after the study was fully explained to them. In accordance with the Helsinki Declaration of 1975 , the study was approved by the local university ethics committee of the Ruhr University Bochum, Germany.

Open Access This article is licensed under a Creative Commons Attribution 4.0 International License, which permits use, sharing, adaptation, distribution and reproduction in any medium or format, as long as you give appropriate credit to the original author(s) and the source, provide a link to the Creative Commons licence, and indicate if changes were made. The images or other third party material in this article are included in the article's Creative Commons licence, unless indicated otherwise in a credit line to the material. If material is not included in the article's Creative Commons licence and your intended use is not permitted by statutory regulation or exceeds the permitted use, you will need to obtain permission directly from the copyright holder. To view a copy of this licence, visit http://creativecommons.org/licenses/by/4.0/.

\section{References}

1. Goodman WK, Grice DE, Lapidus KAB, Coffey BJ (2014) Obsessive-compulsive disorder. Psychiatr Clin N Am 37(3):257-267. https://doi.org/10.1016/j.psc.2014.06.004

2. Klanker M, Feenstra M, Denys D (2013) Dopaminergic control of cognitive flexibility in humans and animals. Front Neurosci 7:201. https://doi.org/10.3389/fnins.2013.00201\#

3. Pittenger C, Bloch MH, Williams K (2011) Glutamate abnormalities in obsessive compulsive disorder: neurobiology, pathophysiology, and treatment. Pharmacol Ther 132(3):314-332. https://doi. org/10.1016/j.pharmthera.2011.09.006

4. Nakao T, Okada K, Kanba S (2014) Neurobiological model of obsessive-compulsive disorder: evidence from recent neuropsychological and neuroimaging findings. Psychiatry Clin Neurosci 68(8):587-605. https://doi.org/10.1111/pcn.12195

5. Burguière E, Monteiro P, Mallet L, Feng G, Graybiel AM (2015) Striatal circuits, habits, and implications for obsessive-compulsive disorder. Curr Opin Neurobiol 30:59-65. https://doi.org/10. 1016/j.conb.2014.08.008

6. Menzies L, Chamberlain SR, Laird AR, Thelen SM, Sahakian BJ, Bullmore ET (2008) Integrating evidence from neuroimaging and neuropsychological studies of obsessive-compulsive disorder: the orbitofronto-striatal model revisited. Neurosci Biobehav Rev 32(3):525-549. https://doi.org/10.1016/j.neubi orev.2007.09.005

7. Huang WJ, Chen WW, Zhang X (2015) The neurophysiology of P 300-an integrated review. Eur Rev Med Pharmacol Sci 19(8):1480-1488

8. Mavrogiorgou P, Juckel G, Frodl T, Gallinat J, Hauke W, Zaudig M, Dammann G et al (2002) P300 subcomponents in obsessivecompulsive disorder. J Psychiatr Res 36(6):399-406. https://doi. org/10.1016/s0022-3956(02)00055-9

9. Miyata A, Matsunaga H, Kiriike N, Iwasaki Y, Takei Y, Yamagami S (1998) Event-related potentials in patients with obsessivecompulsive disorder. Psychiatry Clin Neurosci 52(5):513-518. https://doi.org/10.1046/j.1440-1819.1998.00427.x

10. Morault PM, Bourgeois M, Laville J, Bensch C, Paty J (1997) Psychophysiological and clinical value of event-related potentials in obsessive-compulsive disorder. Biol Psychiatry 42(1):46-56. https://doi.org/10.1016/S0006-3223(96)00228-4

11. Towey J, Bruder G, Hollander E, Friedman D, Erhan H, Liebowitz M, Sutton S (1990) Endogenous event-related potentials in obsessive-compulsive disorder. Biol Psychiatry 28(2):92-98. https:// doi.org/10.1016/0006-3223(90)90626-d

12. Towey J, Bruder G, Tenke C, Leite P, DeCaria C, Friedman D, Hollander E (1993) Event-related potential and clinical correlates of neurodysfunction in obsessive-compulsive disorder. Psychiatry Res 49(2):167-181. https://doi.org/10.1016/0165-1781(93) 90103-n

13. Andreou C, Leicht G, Popescu V, Pogarell O, Mavrogiorgou P, Rujescu D, Giegling I et al (2013) P300 in obsessive-compulsive disorder: source localization and the effects of treatment. J Psychiatr Res 47(12):1975-1983. https://doi.org/10.1016/j.jpsychires. 2013.09.003

14. Gohle D, Juckel G, Mavrogiorgou P, Pogarell O, Mulert C, Rujescu D, Giegling I et al (2008) Electrophysiological evidence for cortical abnormalities in obsessive-compulsive disorder-a replication study using auditory event-related P300 subcomponents. J Psychiatr Res 42(4):297-303. https://doi.org/10.1016/j. jpsychires.2007.01.003

15. Towey JP, Tenke CE, Bruder GE, Leite P, Friedman D, Liebowitz M, Hollander E (1994) Brain event-related potential correlates of overfocused attention in obsessive-compulsive disorder. 
Psychophysiology 31(6):535-543. https://doi.org/10.1111/j.14698986.1994.tb02346.x

16. Malloy P, Rasmussen S, Braden W, Haier RJ (1989) Topographic evoked potential mapping in obsessive-compulsive disorder: evidence of frontal lobe dysfunction. Psychiatry Res 28(1):63-71. https://doi.org/10.1016/0165-1781(89)90198-4

17. Sanz M, Molina V, Martin-Loeches M, Calcedo A, Rubia FJ (2001) Auditory P300 event related potential and serotonin reuptake inhibitor treatment in obsessive-compulsive disorder patients. Psychiatry Res 101(1):75-81. https://doi.org/10.1016/ s0165-1781(00)00250-X

18. Ma Q, Wang X, Shu L, Dai S (2008) P300 and categorization in brand extension. Neurosci Lett 431(1):57-61. https://doi.org/10. 1016/j.neulet.2007.11.022

19. Polezzi D, Daum I, Rubaltelli E, Lotto L, Civai C, Sartori G, Rumiati R (2008) Mentalizing in economic decision-making. Behav Brain Res 190(2):218-223. https://doi.org/10.1016/j.bbr. 2008.03.003

20. Polezzi D, Sartori G, Rumiati R, Vidotto G, Daum I (2010) Brain correlates of risky decision-making. Neuroimage 49(2):18861894. https://doi.org/10.1016/j.neuroimage.2009.08.068

21. Rigoni D, Polezzi D, Rumiati R, Guarino R, Sartori G (2010) When people matter more than money: an ERPs study. Brain Res Bull 81(4-5):445-452. https://doi.org/10.1016/j.brainresbull. 2009.12.003

22. Yeung N, Sanfey AG (2004) Independent coding of reward magnitude and valence in the human brain. J Neurosci 24(28):62586264. https://doi.org/10.1523/JNEUROSCI.4537-03.2004

23. He JM, Huang XT, Yuan H, Chen YG (2012) Neural activity in relation to temporal distance: differences in past and future temporal discounting. Conscious Cogn 21(4):1662-1672. https://doi. org/10.1016/j.concog.2012.08.006

24. Li JZ, Gui DY, Feng CL, Wang WZ, Du BQ, Gan T, Luo YJ (2012) Victims' time discounting 2.5 years after the Wenchuan earthquake: an ERP study. PLoS ONE 7(7):e40316. https://doi. org/10.1371/journal.pone.0040316

25. Wang J, Chen J, Lei Y, Li P (2014) P300, not feedback errorrelated negativity, manifests the waiting cost of receiving reward information. NeuroReport 25(13):1044-1048. https://doi.org/10. 1097/WNR.0000000000000226

26. Wu H, Gui D, Lin W, Gu R, Zhu X, Liu X (2016) The procrastinators want it now: behavioral and event-related potential evidence of the procrastination of intertemporal choices. Brain Cogn 107:16-23. https://doi.org/10.1016/j.bandc.2016.06.005

27. Brevers D, Bechara A, Cleeremans A, Noël X (2013) Iowa Gambling Task (IGT): twenty years after-gambling disorder and IGT. Front Psychol 4:665. https://doi.org/10.3389/fpsyg.2013.00665

28. Brand M, Labudda K, Markowitsch HJ (2006) Neuropsychological correlates of decision-making in ambiguous and risky situations. Neural Netw 19(8):1266-1276. https://doi.org/10.1016/j. neunet.2006.03.001

29. Cavedini P, Zorzi C, Piccinni M, Cavallini MC, Bellodi L (2010) Executive dysfunctions in obsessive-compulsive patients and unaffected relatives: searching for a new intermediate phenotype. Biol Psychiatry 67(12):1178-1184. https://doi.org/10.1016/j.biops ych.2010.02.012

30. Starcke K, Tuschen-Caffier B, Markowitsch HJ, Brand M (2009) Skin conductance responses during decisions in ambiguous and risky situations in obsessive-compulsive disorder. Cogn Neuropsychiatry 14(3):199-216. https://doi.org/10.1080/1354680090 2996831

31. Starcke K, Tuschen-Caffier B, Markowitsch HJ, Brand M (2010) Dissociation of decisions in ambiguous and risky situations in obsessive-compulsive disorder. Psychiatry Res 175(1-2):114120. https://doi.org/10.1016/j.psychres.2008.10.022
32. Zhang L, Dong Y, Ji Y, Zhu C, Yu F, Ma H, Chen X, Wang K (2015) Dissociation of decision making under ambiguity and decision making under risk: a neurocognitive endophenotype candidate for obsessive-compulsive disorder. Prog Neuropsychopharmacol Biol Psychiatry 57:60-68. https://doi.org/10.1016/j.pnpbp. 2014.09.005

33. MacKillop J, Amlung MT, Few LR, Ray LA, Sweet LH, Munafò MR (2011) Delayed reward discounting and addictive behavior: a meta-analysis. Psychopharmacology 216(3):305-321. https://doi. org/10.1007/s00213-011-2229-0

34. Stanger C, Elton A, Ryan SR, James GA, Budney AJ, Kilts CD (2013) Neuroeconomics and adolescent substance abuse: individual differences in neural networks and delay discounting. J Am Acad Child Adolesc Psychiatry 52(7):747-755.e6. https://doi.org/ 10.1016/j.jaac.2013.04.013

35. Pinto A, Steinglass JE, Greene AL, Weber EU, Simpson HB (2014) Capacity to delay reward differentiates obsessive-compulsive disorder and obsessive-compulsive personality disorder. Biol Psychiatry 75(8):653-659. https://doi.org/10.1016/j.biops ych.2013.09.007

36. Peters J, Büchel C (2010) Episodic future thinking reduces reward delay discounting through an enhancement of prefrontal-mediotemporal interactions. Neuron 66(1):138-148. https://doi.org/10. 1016/j.neuron.2010.03.026

37. Mavrogiorgou P, Enzi B, Steinmann S, Mulert C, Juckel G (2018) Relationship between neuroanatomical and serotonergic hypotheses of obsessive-compulsive disorder: a combined functional magnetic resonance imaging-evoked potential study. J Clin Psychiatry. https://doi.org/10.4088/JCP.17m11811

38. Polich J (2007) Updating P300: an integrative theory of P3a and P3b. Clinical neurophysiology. Clin Neurophysiol 118(10):2128 2148. https://doi.org/10.1016/j.clinph.2007.04.019

39. American Psychiatric Association (2000) Diagnostic and statistical manual of mental disorders: DSM-IV-TR, 4th edn. American Psychiatric Association, Washington

40. Dilling H (Ed) (1999) Taschenführer zur ICD-10 klassifikation psychischer störungen: mit glossar und diagnostischen kriterien ICD-10, DCR-10 (1. Aufl) Huber, Bern, Göttingen, Toronto, Seattle

41. Ackenheil M, Stotz G, Dietz-Bauer R (1997) MINI PLUS: Version 4.5. München, Germany

42. Sheehan DV, Lecrubier Y, Sheehan KH, Amorim P, Janavs J, Weiller E, Hergueta T et al (1998) The Mini-International Neuropsychiatric Interview (MINI): the development and validation of a structured diagnostic psychiatric interview for DSM-IV and ICD-10. J Clin Psychiatry 59(Suppl 20):22-33 (Quiz:34-57)

43. Goodman WK, Price LH, Rasmussen SA, Mazure C, Fleischmann RL, Hill CL, Heninger GR, Charney DS (1989) The Yale-brown obsessive compulsive scale. I. Development, use, and reliability. Arch Gen Psychiatry 46(11):1006-1011. https://doi.org/10.1001/ archpsyc. 1989.01810110048007

44. Goodman WK, Price LH, Rasmussen SA, Mazure C, Delgado P, Heninger GR, Charney DS (1989) The Yale-brown obsessive compulsive scale. II. Validity. Arch Gen Psychiatry 46(11):1012 1016. https://doi.org/10.1001/archpsyc. 1989.01810110054008

45. Hodgson RJ, Rachman S (1977) Obsessional-compulsive complaints. Behav Res Ther 15(5):389-395. https://doi.org/10.1016/ 0005-7967(77)90042-0

46. Hamilton M (1967) Development of a rating scale for primary depressive illness. Br J Soc Clin Psychol 6(4):278-296. https:// doi.org/10.1111/j.2044-8260.1967.tb00530.x

47. Beck AT, Ward CH, Mendelson M, Mock J, Erbaugh J (1961) An inventory for measuring depression. Arch Gen Psychiatry 4:561-571. https://doi.org/10.1001/archpsyc.1961.0171012003 1004 
48. Spielberger CD (1970) Manual for the state-trait anxiety inventory: self-evaluation questionnaire. Consulting Psychologists Press, Palo Alto

49. Laux L, Spielberger CD (1981) Das State-Trait-Angstinventar: STAI; theoretische Grundlagen und Handanweisung. Beltz-Test. Beltz, Weinheim

50. Guy W, Bonato RR (1970) Manual for the ECDEU assessment battery. Department of Health, Education, and Welfare, Bethesda

51. Morosini PL, Magliano L, Brambilla L, Ugolini S, Pioli R (2000) Development, reliability and acceptability of a new version of the DSM-IV Social and Occupational Functioning Assessment Scale (SOFAS) to assess routine social functioning. Acta Psychiatr Scand 101(4):323-329

52. Barratt ES (1959) Anxiety and impulsiveness related to psychomotor efficiency. Percept Mot Skills 9(3):191-198. https://doi.org/ 10.2466/PMS.1959.9.3.191

53. Preuss UW, Rujescu D, Giegling I, Koller G, Bottlender M, Engel RR, Möller HJ, Soyka M (2003) Evaluation der deutschen Version der Barratt Impulsiveness Scale (BIS 5). Fortschr Neurol Psychiatr 71(10):527-534. https://doi.org/10.1055/s-2003-42872

54. Borkenau P, Ostendorf F (1993) NEO-Fünf-Faktoren-Inventar (NEO-FFI) nach Costa und McCrae: Handanweisung. Hogrefe, Göttingen

55. Lehrl S, Triebig G, Fischer B (1995) Multiple choice vocabulary test MWT as a valid and short test to estimate premorbid intelligence. Acta Neurol Scand 91(5):335-345. https://doi.org/10. 1111/j.1600-0404.1995.tb07018.x

56. Polich J (2007) Updating P300: an integrative theory of P3a and P3b. Clin Neurophysiol 118(10):2128-2148. https://doi.org/10. 1016/j.clinph.2007.04.019

57. Pascual-Marqui RD (2002) Standardized low-resolution brain electromagnetic tomography (sLORETA): technical details. Methods Find Exp Clin Pharmacol 24(Suppl D):5-12

58. Nichols TE, Holmes AP (2002) Nonparametric permutation tests for functional neuroimaging: a primer with examples. Hum Brain Mapp 15:R691-R695. https://doi.org/10.1002/hbm.1058

59. Whitlock JR (2017) Posterior parietal cortex. Curr Biol 27(14):R691-R695. https://doi.org/10.1016/j.cub.2017.06.007

60. Mavrogiorgou P, Enzi B, Klimm AK, Köhler E, Roser P, Norra C, Juckel G (2017) Serotonergic modulation of orbitofrontal activity and its relevance for decision making and impulsivity. Hum Brain Mapp 38(3):1507-1517. https://doi.org/10.1002/hbm.23468

61. Brett M, Anton JL, Valabrgue R, Poline JB (2002) Region of interest analysis using an spm toolbox [abstract]. Presented at the 8 th international conference on functional mapping of the human brain, June 2-6. Sendai, Japan

62. Rector NA, Hood K, Richter MA, Bagby RM (2002) Obsessivecompulsive disorder and the five-factor model of personality: assessing the distinction and overlap with major depressive disorder. Behav Res Ther 40:1205-1219. https://doi.org/10.1016/ S0005-7967(02)00024-4

63. Samuels J, Nestadt G, Bienvenu OJ, Costa PT Jr, Riddle MA, Liang KY, Hoehn-Saric R, Grados MA, Cullen BA (2000) Personality disorders and normal personality dimensions in obsessivecompulsive disorder. Br J Psychiatry 177:457-462. https://doi. org/10.1192/bjp.177.5.457

64. Rector NA, Richter MA, Bagby RM (2005) The impact of personality on symptom expression in obsessive-compulsive disorder. J Nerv Ment Dis 193:231-236. https://doi.org/10.1097/01.nmd. 0000158378.14019.89

65. Dayan-Riva A, Berger A, Anholt GE (2019) Early cognitive processes in OCD: an ERP study. J Affect Disord 246:429-436. https://doi.org/10.1016/j.jad.2018.12.109

66. Linden DEJ (2005) The p300: where in the brain is it produced and what does it tell us? Neuroscientist 11(6):563-576. https:// doi.org/10.1177/1073858405280524

67. Bellebaum C, Polezzi D, Daum I (2010) It is less than you expected: the feedback-related negativity reflects violations of reward magnitude expectations. Neuropsychologia 48(11):33433350. https://doi.org/10.1016/j.neuropsychologia.2010.07.023

68. Sachdev PS, Malhi GS (2005) Obsessive-compulsive behaviour: a disorder of decision-making. Aust N Z J Psychiatry 39(9):757763. https://doi.org/10.1080/j.1440-1614.2005.01680.x

69. Gruner P, Anticevic A, Lee D, Pittenger C (2016) Arbitration between action strategies in obsessive-compulsive disorder. Neuroscientist 22(2):188-198. https://doi.org/10.1177/1073858414 568317

70. Pushkarskaya H, Tolin D, Ruderman L, Kirshenbaum A, Kelly JM, Pittenger C, Levy I (2015) Decision-making under uncertainty in obsessive-compulsive disorder. J Psychiatr Res 69:166173. https://doi.org/10.1016/j.jpsychires.2015.08.011

71. Okasha A, Rafaat M, Mahallawy N, El Nahas G, El Dawla AS, Sayed M, El Kholi S (2000) Cognitive dysfunction in obsessivecompulsive disorder. Acta Psychiatr Scand 101(4):281-285

72. Benzina N, Mallet L, Burguière E, N'Diaye K, Pelissolo A (2016) Cognitive dysfunction in obsessive-compulsive disorder. Curr Psychiatry Rep 18(9):80. https://doi.org/10.1007/ s11920-016-0720-3

73. Kenemans J, Kähkönen S (2011) How human electrophysiology informs psychopharmacology: from bottom-up driven processing to top-down control. Neuropsychopharmacol 36:26-51. https:// doi.org/10.1038/npp.2010.157

74. Fettes P, Schulze L, Downar J (2017) Cortico-striatal-thalamic loop circuits of the orbitofrontal cortex: promising therapeutic targets in psychiatric illness. Front Syst Neurosci 11:25. https:// doi.org/10.3389/fnsys.2017.00025 